\title{
Household Solid Waste Generation and Composition: A Case Study in Palapye, Botswana
}

\author{
Ronald Dikole, Moatlhodi Wise Letshwenyo (D) \\ Department of Civil and Environmental Engineering, Faculty of Engineering and Technology, Botswana International University \\ of Science and Technology, Palapye, Botswana \\ Email: ronald.dikole@studentmail.biust.ac.bw, letshwenyom@biust.ac.bw
}

How to cite this paper: Dikole, R. and Letshwenyo, M.W. (2020) Household Solid Waste Generation and Composition: A Case Study in Palapye, Botswana. Journal of Environmental Protection, 11, 110-123. https://doi.org/10.4236/jep.2020.112008

Received: January 3, 2020

Accepted: February 22, 2020

Published: February 25, 2020

Copyright $\odot 2020$ by author(s) and Scientific Research Publishing Inc. This work is licensed under the Creative Commons Attribution International License (CC BY 4.0).

http://creativecommons.org/licenses/by/4.0/ (c) (i) Open Access

\begin{abstract}
The purpose of this case study was to conduct a case study in the generation rate, composition, and characterise solid wastes from low, middle and high income households during weekdays and weekends in Palapye, Botswana. The study was conducted through sampling and analysis of the wastes from sampled households from each of the three categories. Palapye village does not have an engineered solid waste management system in place; hence the study can be used as a starting point. The village is rapidly urbanising with many shopping complexes coming up which will generate high amounts of solid wastes of different compositions. The lowest generation rate was 0.038 $\mathrm{kg} / \mathrm{capita} /$ day from low income households during weekends and the highest was $0.364 \mathrm{~kg} / \mathrm{capita} /$ day generated from high income households during weekends. The composition of the wastes was dominated by food wastes ranging from $46.44 \%$ to $80.78 \%$ with low income households generating the highest percentage during weekdays. The average moisture contents of samples from low, middle and high income households were $71 \% \pm 0.0 \%, 66.3 \%$ $\pm 1.25 \%$ and $74.3 \% \pm 2.2 \%$ respectively during weekdays compared to $77 \% \pm$ $0.0 \%, 66.5 \% \pm 3.5 \%$ and $69.3 \% \pm 3.3 \%$ during weekends. The average moisture contents from low, middle and high income households were $71 \% \pm$ $0.0 \%, 66.3 \% \pm 1.25 \%$ and $74.3 \% \pm 2.2 \%$ respectively during weekdays compared to $77 \% \pm 0.0 \%, 66.5 \% \pm 3.5 \%$ and $69.3 \% \pm 3.3 \%$ during weekends. The results can be used as part of the waste management planning purpose by the Administrative Council of the area.
\end{abstract}

\section{Keywords}

Food Wastes, High Income Households, Middle Income Households, Lower Income Households, Solid Waste Generation Rate 


\section{Introduction}

Knowledge of waste generation rate, types of wastes generated, generation rate per income level and types of wastes generated per income level as well as generation rates during weekdays and weekends can help in planning for solid waste management system. Both physical and chemical composition of the wastes can help in determining the energy value of the wastes hence the possibility of the wastes as energy sources. Human activities create wastes which need handling, storage, collection and disposal as they pose risk to the environment and public health [1]. Economic growth, industrialisation and improved living standards in cities across the world have been reported as factors that have contributed to increased solid wastes generation and challenges associated with management of solid wastes [2]. Solid wastes generated should be managed accordingly in a systematic engineered approach. However, studies have reported poor waste management especially in developing countries. For instance [1] reported that poor collection and inadequate transportation contribute to the accumulation of wastes in many cities. It has been reported that most of the municipal solid wastes are generated from households (55\% to $80 \%$ ) and $10 \%$ to $30 \%$ from commercial areas [3]. These wastes are heterogeneous in nature and vary in physical characteristics depending on their sources. The heterogeneity is a disadvantage as wastes have to be separated for recycling to be achieved [3].

The composition of the solid wastes depends on a number of factors such as food habits, cultural traditions, climate and income [1]. Municipal solid waste management involves a collection of stages namely generation, storage, separation, collection, energy recovery and disposal activities [4]. Generation of solid wastes depends on factors such as social behaviour, income level, sources, population, climate, industrial production and market for waste materials [1]. Miezah et al. [3] who conducted a study on municipal solid waste characterisation and quantification as a measure towards effective waste management in Ghana found that the average generation rates in ten regional capitals were 0.51 $\mathrm{kg} /$ person/day and $0.47 \mathrm{~kg} /$ person/day for areas outside the regional capitals. Generation rate was attributed to location in the district, geographic location and income and household size. Knowing the amount and composition of wastes generated is important for the planning, operation and optimisation of waste management systems [5]. Poor organisation of waste collection has been reported for instance, in India, with poor storage at source and poor design of collection bins leading to poor collection efficiency [1]. Emphasis is now on material recovery and utilisation of some of the wastes as a source of energy. Transportation has been identified as one of the factors that contribute to inadequate solid waste management [6]. Failure to collect and transport solid wastes has in most cases resulted in rodents and dogs vandalising storage facilities therefore wastes scattered over streets. Some cases have been reported where wastes disposal sites are inadequate to serve the user population as the volume of the generated solid wastes is overwhelming [7]. Some wastes are disposed of at 
dumping sites instead of engineered landfills or other disposal facilities such as incinerators. Disposal of wastes in India has been reported to be lacking and in most cases composting, waste to energy being the main disposal methods [1]. It has been reported that poor waste management situation has led to high incidences of sanitation related illnesses such as cholera, intestinal worms and typhoid [7]. It has been reported by Kgosietsile and Zhaohui [8], that Botswana's population has increased by $5 \%$ during the past 5 years. The population increase has put a lot of pressure on the waste management systems of Botswana. Table 1 shows the estimation of the annual waste quantities in Botswana.

Table 1 shows that there are different types of waste that are generated in Botswana hence the need to have proper and effective management system. Botswana Waste Management Strategy (BWMS) established in 1998 is responsible for managing the waste management issues and problems. Growing economy and population in Gaborone (capital city of Botswana) has resulted in high demands of goods and services therefore high generation of solids wastes. In addition, there is minimal reuse and recycling due to lack of awareness and insufficient environmental policy [9]. A study by Kgosietsile and Zhaohui [8] has reported serious gaps in the achievement of long term sustainability of waste management practices in Botswana. As such there is need to have waste management systems in the different towns, cities and villages in the country. Every waste management system begins with the knowing the source, generation and types and composition of the wastes.

The purpose of this case study was to evaluate the generation rate, physical composition of the solid wastes by conducting a case study in Palapye Botswana. The case study was conducted on the income level of households during weekdays and weekends. Palapye village was chosen because at present there is no engineered solid waste management system in place. This study can be used as a starting point for developing a proper solid waste management system which involves the generation rate at all income levels, waste compositions which

Table 1. Estimates of Botswana's annual waste quantities [8].

\begin{tabular}{cc}
\hline Waste type & Quantity (tonnes/year) \\
\hline Solid waste at landfill & 270,425 \\
Solid hazardous waste & 1560 \\
Hazardous clinical waste & 2500 \\
Scrap metal waste & 20,000 \\
Household waste & 250,000 \\
\hline Miscellaneous waste & \\
\hline Liquid hazardous waste & 34,610 \\
Tires & 90,651 \\
Household dry cell batteries & 24,000 \\
Lead acid batteries & 46,000 \\
Oil waste (1000 litres annually) & 5600 \\
\hline
\end{tabular}


will also help in practising reuse and recycle hence types of storage containers and transportation to be used. Few studies have been conducted to compare the generation rate as well as the composition of the solid wastes during weekdays and weekends. Knowing the generation and composition of the solids wastes during weekdays and weekends can help during the determination of transport size, types of transport to use as well as the disposal system to plan for. The research institution especially the department that conducted the research has been approached by the Administrative Council of the area to help in issues such as storm water drainage and solid waste management system where the case study was conducted. The results obtained during this study will be used as starting point when further conducting a research for the Council.

\section{Study Area}

Palapye town is located in central district of Botswana with population estimation of 36,211 as reported by [10]. It is $70 \mathrm{~km}$ north of the tropic of Capricorn along the road linking the capital city, Gaborone and Francistown, which is the second largest City in the country. The study areas covered households in Extension 4 located in the centre of the town.

\section{Materials and Methods}

\subsection{Waste Sampling and Procedure}

Sampling of wastes from households was achieved by categorising the houses into high, middle and low income status (Table 2) as per [3]. The sizes of households sampled ranged from 3 to 5 persons per household. The sampling period lasted for 4 weeks. Households in each category were sampled and given plastic bags to place wastes during weekdays and weekends. The bags were collected on Mondays and Fridays after which the wastes were sorted out at the University laboratory to determine composition of the wastes.

Table 2. Criteria for categorizing households according to income status [3].

\begin{tabular}{ccc}
\hline Low income & Middle income & High income \\
Mostly tenants & Both tenants and owners & Occupants own house \\
Low population density & Middle population density & High population density \\
Unreliable electricity & Unreliable electricity & Reliable electricity \\
Poor community layout & Nometimes & Good community layout \\
Poor water supply & Unreliable water supply & Potable water supply \\
Poor security & Moderate security & High level security \\
Poor road and drainage & Average road and drainage & Good road and drainage \\
systems & & systems
\end{tabular}




\subsection{Household Waste Generation}

The per capita waste generation of each household was calculated as per [11] by dividing total number of waste produced in each household with the number of people living in the house per the number of days the waste was generated.

$$
\text { Generation rate }\left(\frac{\mathrm{kg}}{\text { capita } \cdot \text { day }}\right)=\frac{\text { mass of solid waste }(\mathrm{kg})}{\text { number of people } \times \text { number of days }}
$$

\subsection{Sorting Procedure}

The wastes from each household were sorted out according to composition. Sorting was conducted at the university laboratory by separating the wastes into plastics, glass, food, paper and cardboard, textile, yard waste, and tin (Figure 1). The sorted waste was weighed to determine the mass and volume of each waste composition using electronic scale and calibrated buckets after compaction.

A weighing scale was used to weigh the different compositions of the wastes after sorting to determine the mass of each waste composition. A container of known volume and mass was used to measure the volume of the samples (Figure 2). Knowing the mass and volume of each waste composition, the percentage for each waste type in a sample was calculated.

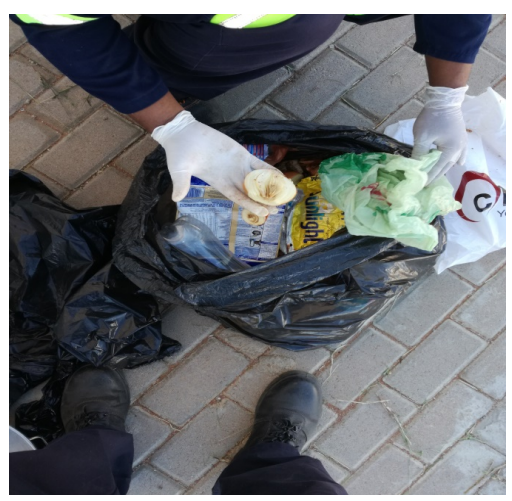

Figure 1. Wastes being sorted for measurement.

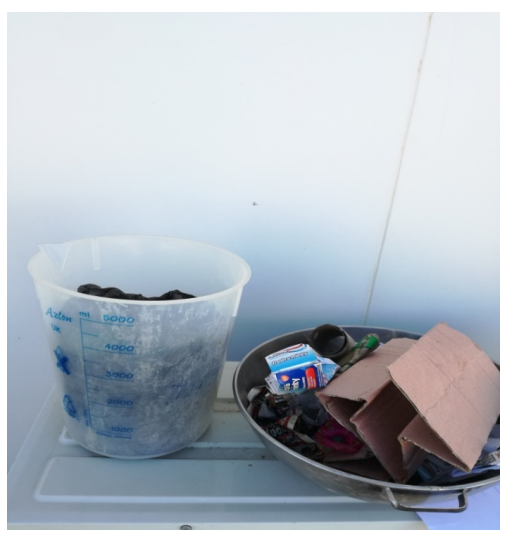

Figure 2. Determining the volume and mass of different waste components. 


\subsection{Moisture Content}

For determining the moisture content of solid waste, the waste sample was weighed as discarded which represented its wet weight. These samples were then dried in an oven at a temperature of $75^{\circ} \mathrm{C}$ for 24 hours and then weighed measured again. The weight loss was then expressed as a percentage, which represents moisture content. The moisture content was calculated according to the equation below:

$$
\text { Moisture content }(\%)=\frac{\text { Original weight }- \text { Final weight }(\text { dry })}{\text { Original weight }} \times 100
$$

\subsection{Statistical Analysis}

Microsoft Excel was used to determine whether there was any significant difference between wastes generated during weekdays and weekends.

\section{Results and Discussion}

\subsection{Household Solid Waste Generation Rates}

Solid waste generation rates from all the income levels during weekdays and weekends are shown in Figure 3.

It was observed that waste generation rate for low income households was high $(0.114 \pm 0.0 \mathrm{~kg} / \mathrm{cap} /$ day $)$ during weekdays than weekends $(0.038 \pm 0.0$ $\mathrm{kg} / \mathrm{cap} /$ day), which was a $67 \%$ reduction. In contrast lower generation rate was recorded during weekdays compared to weekends in middle and high income households. The generation rates in middle income households increased by $106 \%$ from weekdays to weekends. The same trend was observed in the case of high income households where generation rate from weekdays increased by $250 \%$ during weekends. There was a significant difference between waste generated during weekdays and weekends for middle income households $(\mathrm{p}<0.05)$. The same was observed for high income households with $\mathrm{p}<0.05$. These results suggest that the waste generation rates during weekdays and weekends differed. Troschinetz and Mihelcic [12] reported that waste generation in developing

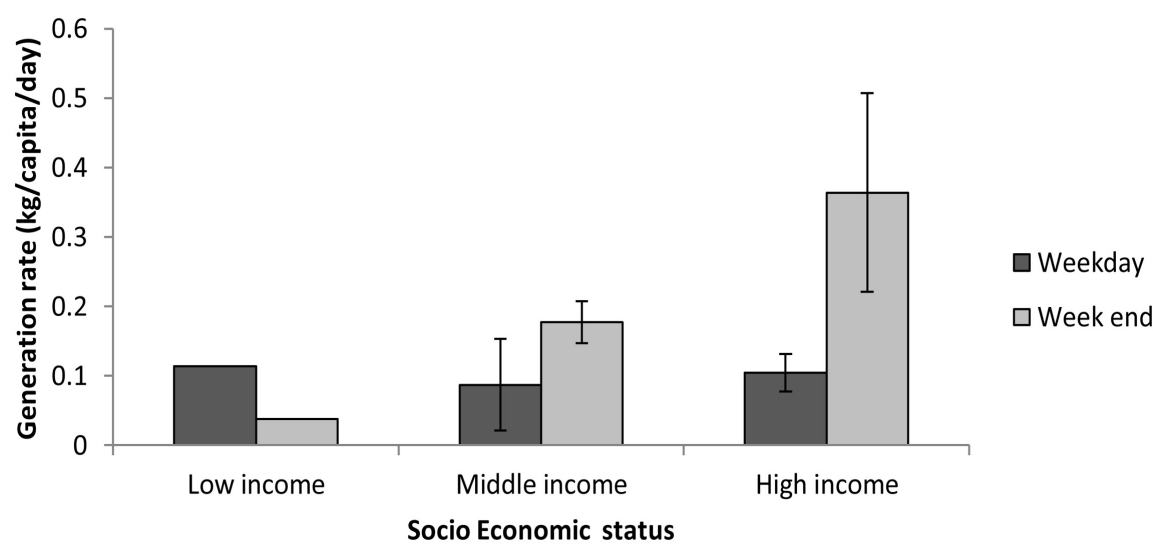

Figure 3. Generation rates of solid wastes in low, middle and high income households. 
countries of Bhutan, Botswana and Mexico is approximately $0.3 \mathrm{~kg} / \mathrm{capita} /$ day which is similar to high income generation rate observed in this study $(0.364 \pm$ $0.14 \mathrm{~kg} / \mathrm{cap} . \mathrm{d}$ ). Bolaane and Ali [13] reported average generation rates of 0.35, 0.35 and $0.27 \mathrm{~kg} / \mathrm{cap} /$ day for low, medium and high income categories in Gaborone, Botswana which was less than $0.364 \pm 0.14 \mathrm{~kg} / \mathrm{cap} / \mathrm{d}$ observed under high income households in this study. High waste generation during weekends was also observed by Jadoon and Adila [14] who reported highest quantities generated and collected on Monday for all the income groups in their study of assessing factors affecting household solid waste generation in Gulberg town, Pakistan. The reason was attributed to activities on Sundays as people spend the day at their homes and weekly clean-up day was also Sunday hence high waste generation. This could be the same reason in this study and in addition most households arrange for parties on Saturdays hence high wastes generated during weekends. This was also reported by Thanh et al. [15] who attributed high generation during weekends to households going for shopping at weekends to buy goods and food they consume that weekend and following days. Households members stay at home during weekend hence generation of wastes would increase. These results are in contrast to the generation rate of a study conducted by Al-Khatib et al. [16] who reported generation rate between $0.68 \mathrm{~kg} / \mathrm{cap} /$ day to $1.02 \mathrm{~kg} / \mathrm{cap} /$ day for Nablus city in Palestine. The difference could be due to different living styles for people in cities which affect generation rates. Similarly, the results contrast the findings by Gomez et al. [17] who reported generation rates of $0.732 \mathrm{~kg} / \mathrm{cap} /$ day and $0.599 \mathrm{~kg} / \mathrm{cap} /$ day for high and low income areas respectively in Mexico. Owamah et al. [18] reported a generation rate of 1.04 $\mathrm{kg} / \mathrm{capita} /$ day in Ogbe-Ijoh community in Nigeria which was larger than the findings in this study. It has been reported that generation rate for sub-urban communities of developing countries is above the estimated range of $0.4-0.6$ $\mathrm{kg} / \mathrm{capita} /$ day [18]. This study has revealed that high income households generated the highest quantities of solid wastes followed by middle income and lastly low income and that is comparable to the study conducted by Jadoon and Adila [14]. The results contrast the finding by Bolaane and Ali [13] who reported that there was no direct proportion of waste generated and income level during their study in Gaborone, Botswana.

\subsection{Physical Composition}

\subsubsection{Lower Income Households}

Figure 4 and Figure 5 show physical composition of solid wastes during weekdays and weekends respectively from low income households. Food wastes occupied the highest portion of the wastes generated during weekdays followed by paper/cardboard and lastly plastic wastes. In contrast, during weekends, there was no food wastes generated but only paper/cardboard and plastic wastes.

The reason no food wastes were generated during weekends might be due to controlled cooking as parents are present during weekends but at work places 


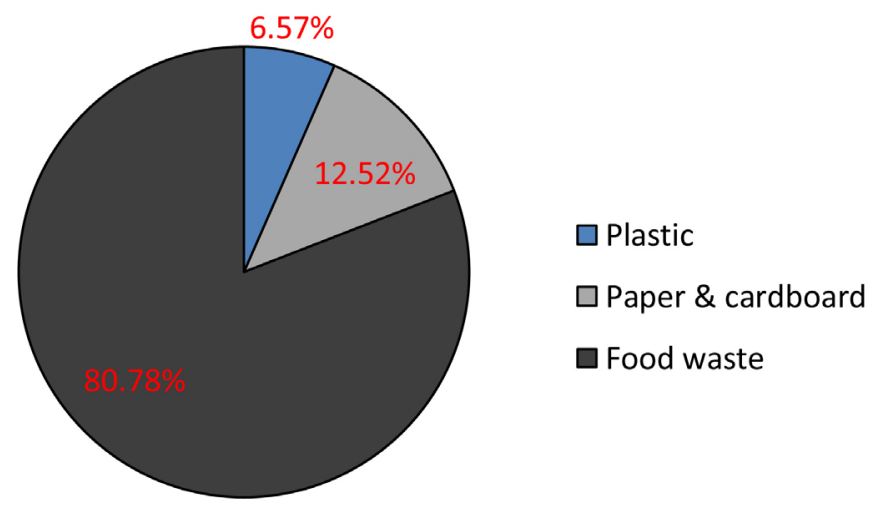

Figure 4. Composition distribution of solid waste from low income households during weekdays.

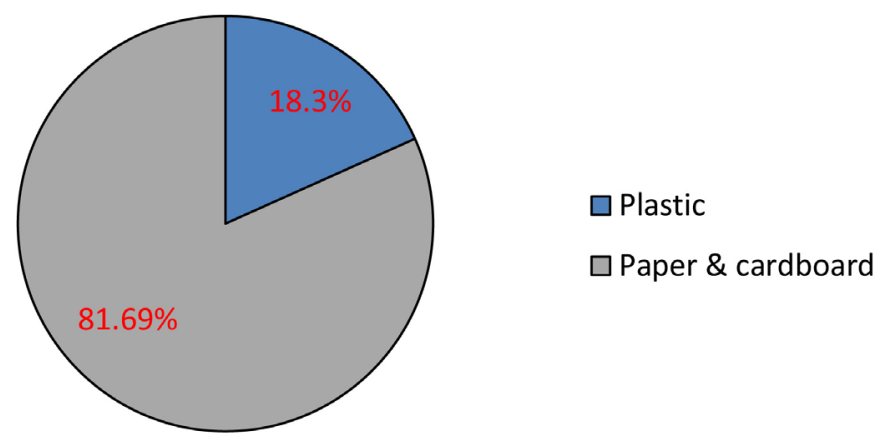

Figure 5. Composition distribution of solid waste from low income households during weekends.

during weekdays resulting in misuse of food by children. It was surprising to find a large percentage of food wastes in low income households where it is expected that food control will be given high priority resulting in low food wastes. Many low income households are provided with food baskets monthly by the Administrative council and this could be the reason for wastage since there will be no food shortage for the families. The food basket is also supplied to each orphan in the household further suggesting that there would be no food shortage until the next supply time. These findings are comparable to studies conducted by Dangi et al. [11] where the composition of organic wastes (food, vegetable trimmings) ranged from $66.50 \%$ to $71.10 \%$ whereas plastics, paper and paper products wastes occupied $4.5 \%-9.2 \%$ and $0.3 \%-12.0 \%$ respectively. The presence of paper and plastic wastes suggest that the wastes are from packaging of some materials such as food, bought by the households. Many retail stores in the town use plastics for packing items bought by their customers which could be the reason for the presence of plastic wastes in the samples.

\subsubsection{Middle Income Households}

Figure 6 and Figure 7 below show the physical composition of solid wastes during weekdays and weekends respectively. Unlike in low income households, in addition the composition included glass and tin waste fractions. In decreasing 


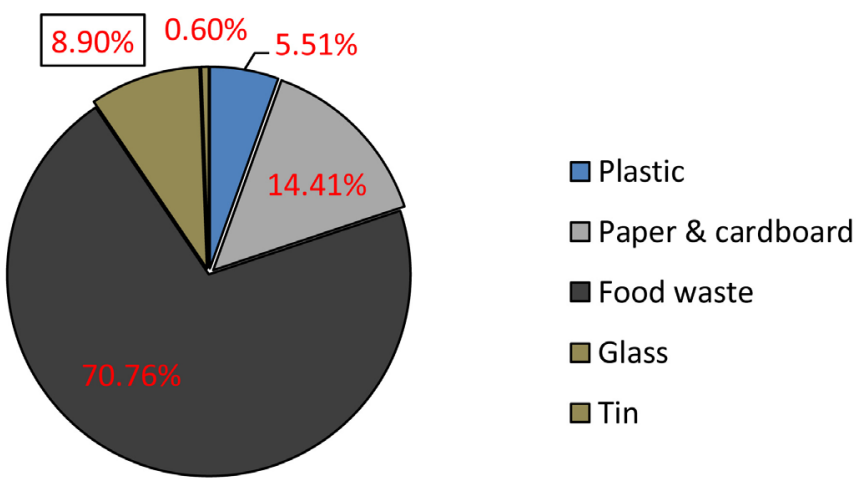

Figure 6. Composition distribution of solid waste from middle income households during weekdays.

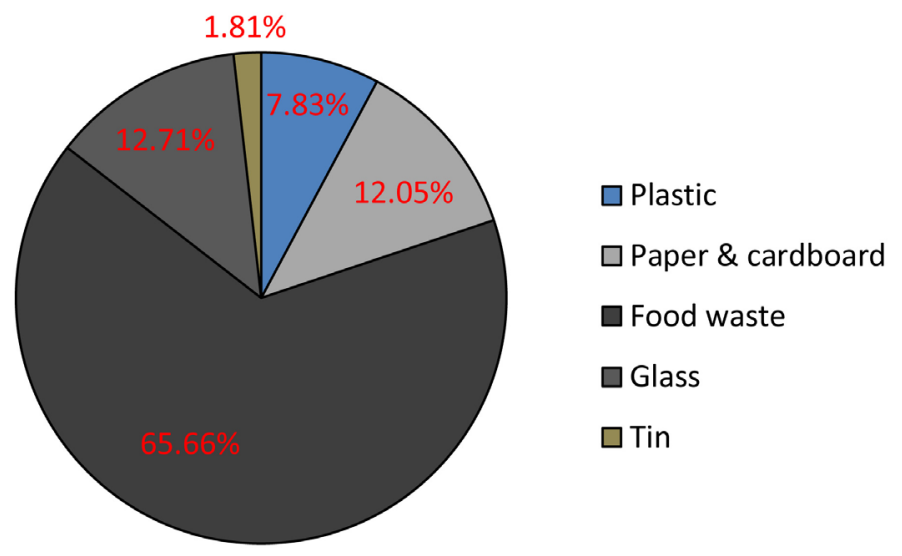

Figure 7. Composition distribution of solid waste from middle income households during weekends.

order, the composition of the wastes was food $>$ paper/cardboard $>$ glass $>$ plastics $>$ tin during weekdays. Similarly to low income households it was observed that food and paper/cardboard dominated the composition. This trend was again observed during weekends where the composition decreased as food > glass $>$ paper/cardboard $>$ plastics $>$ tin components. The glass portion was dominated by beer and soft drink bottles indicating that households have extra income to buy these items. In addition, tin wastes was from food staff.

There was a reduction by $5.1 \%$ in the generation of food wastes during weekends compared to weekdays implying that food is saved during weekends. The other reason could be due to few weekend days (3 days) compared to 4 weekdays hence large quantities of food during weekdays resulting in higher generation of food wastes. Similarly to low income households the reason for large quantity of food wastes generated during weekdays might be due to misuse b children as parents spend most of the time at work places during weekdays.

\subsubsection{High Income Households}

Figure 8 and Figure 9 show the results from high income households during weekdays and weekends respectively. The results still reveal high proportion of 


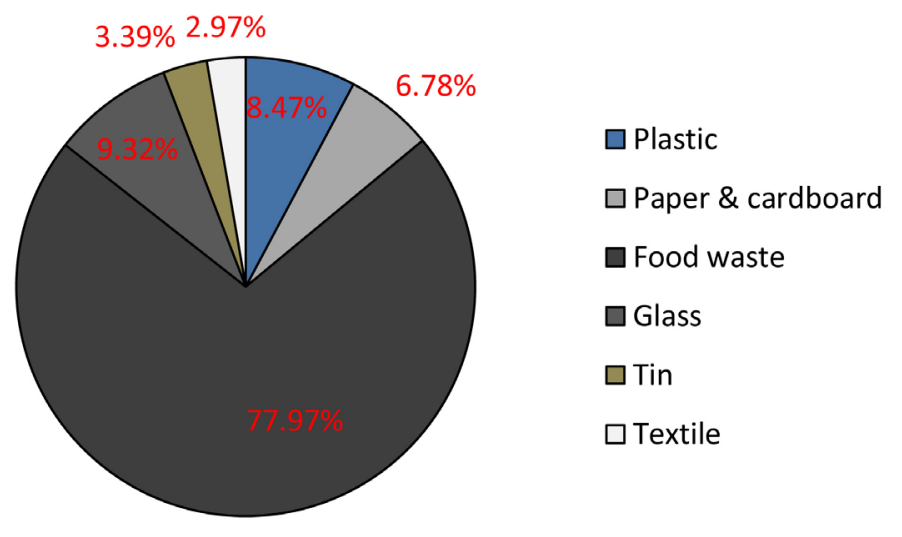

Figure 8. Composition distribution of solid waste from high income households during weekdays.

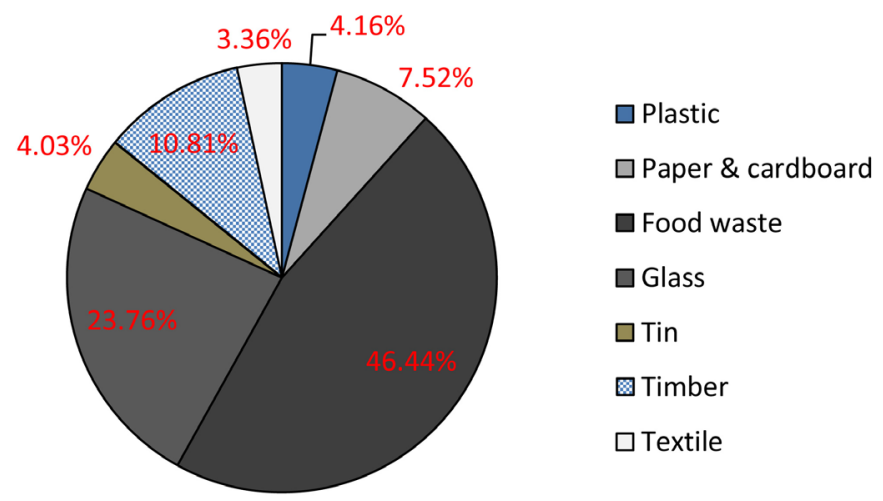

Figure 9. Composition distribution of solid waste from high income households during weekends.

food wastes compared to other wastes and in addition there were new wastes generated which were textile and timber. Though the fraction of food wastes was still high in both cases, the composition had dropped by $31.53 \%$ from weekdays to weekends. These results are larger than the findings by Palanivel and Sulaiman [19] who reported food compositions by weight of $33.60 \%$ and $22.80 \%$ in winter and summer respectively, in Muscat, Oman. In addition there was the presence of timber wastes during weekends which could be due to activities of construction taking place.

These results reveal that as the level of income rises, the composition of wastes generated increases. This could be due to people affording a variety of things which they can purchase and then disposing old or those items they render useless. It was observed that glass wastes were the second dominant composition further suggesting that high income people afford socialising during weekends. The presence of glass, tin, paper/cardboard and plastic wastes suggest that recycling of wastes is not practiced in the area. All these wastes were stored in the same containers further suggesting that no recycling was practised in the town. Public attitudes towards wastes and waste management in the country have been reported as often problematic and no encouragement from the political institu- 
tions [8]. Lack of political pressure towards waste management might have contributed towards lack of solid waste recycling and reuse as observed in this study. Limited technologies and good practices for waste management, lack of equipment for the collection of sorted materials have been reported to hamper the development of waste separation programs [20]. Textile wastes were comparable to the findings by Zhou et al. [21] who reported a composition ranging from $0.60 \%$ to $3.80 \%$ compared $3.36 \%$ observed in this study. Life styles, climate, economic status and region influence the physical composition of wastes [21]. The researchers go on to report that in regions with high living standards, wastes are composed of plastics, paper and textiles mainly. This contrasts the findings in this study where it was observed that food wastes in high income households dominate followed by glass wastes and plastic and paper/cardboard followed. These results suggest high wastage of food in all categories of households studied suggesting a culture of cooking large quantities of food. The results show that organic waste is the highest component in all the samples. The high quantity of food waste has been reported to pose environmental problems as leachate at landfills results from the organic fraction of the solid wastes [19]. At the same time this might not be good for resource recovery. Owamah et al. [18] reported a $77 \%$ of organic wastes in Ogbe-Ijoh community, Nigeria which is similar to the findings in this study. Knowing the composition of solid wastes will help in evaluation of disposal methods as well as planning for resource recovery, reuse, recycle and the types of storage facilities and transportation needed. High percentage of food wastes and papers present could further motivate studies on the possibility of using these wastes for the production of biofuel. In addition, composting possibility using organic wastes can be studied which will be a source of soil amendment for horticulture purposes. The presence of glass and tin fractions in the middle and high income areas can motivate people to embark on recycling and therefore generate income for themselves. Though recycling is encouraged in the country, this study has shown that there is need for public education in this area and this should be supported by the provision of storage containers in each household or at strategic locations for recycling purposes.

\subsection{Moisture Content}

As shown in Figure 10, the average moisture contents of samples from low, middle and high income households was $71 \% \pm 0.0 \%, 66.3 \% \pm 1.25 \%$ and $74.3 \% \pm$ $2.2 \%$ respectively during weekdays compared to $77 \% \pm 0.0 \%, 66.5 \% \pm 3.5 \%$ and $69.3 \% \pm 3.3 \%$ during weekends, and these results are similar. The results are comparable to the findings by Baba and Garba [22]. High moisture content was attributed to large quantity of organic wastes. High moisture content in wastes is an influential factor during separation of recyclables as segregated and clean materials are attractive. But in the case of wastes with high moisture content, materials such as paper and cardboard will not be attractive for recycling.

High moisture content of food wastes results in high moisture content of the 


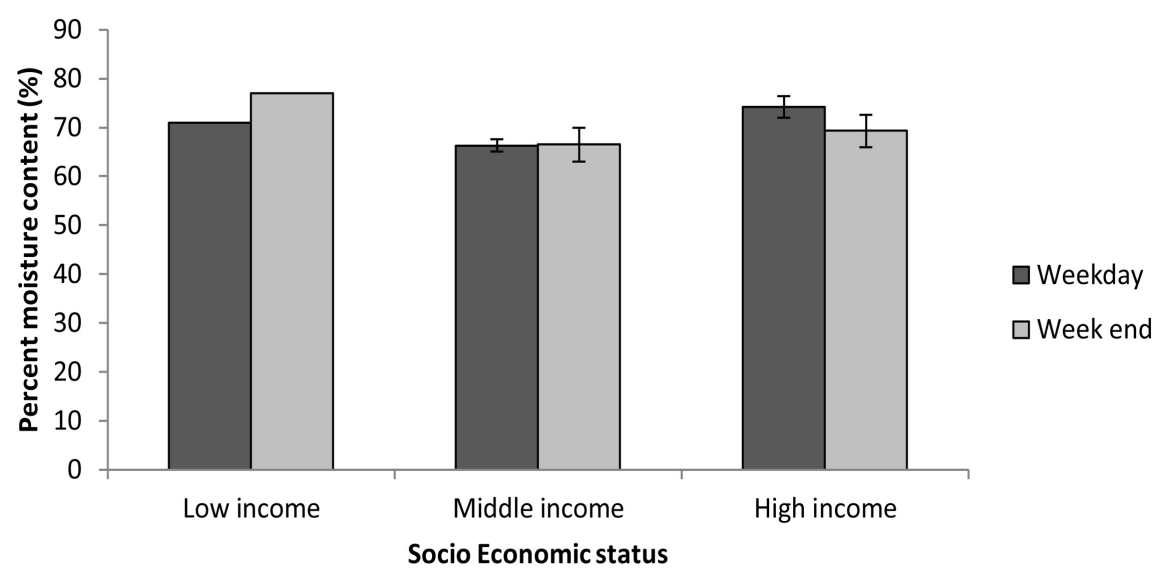

Figure 10. Solid waste moisture content from low, middle and high income households during weekdays and weekends.

overall solid wastes. Since food wastes in this study were found to occupy high percentage, it is eminent that overall the moisture content of the solid wastes will be high.

\section{Conclusion}

The composition of solid wastes in the studied area is mainly dominated by food wastes. Highest quantities of wastes were generated during weekends in middle and high income households but weekdays in low income households. There was a significant difference between wastes generated during weekdays and weekends. Solid wastes generation rate ranged from $0.038 \mathrm{~kg} / \mathrm{capita} /$ day to 0.364 $\mathrm{kg} / \mathrm{capita} /$ day. The high percentage of food wastes could have led to high moisture content observed in waste samples. The findings of this study can be used for planning for solid waste management by the policy makers and technical staff in the study area and towns and villages having similar characteristics to the study area. There is no engineered solid waste disposal site in the area and the results can be a starting point in planning for such. The limitations of the study included short duration since the study was conducted by undergraduate student for one term. It was not possible to observe seasonal variations during the study due to time limitations. It would have been better to include storage, transportation, and disposal in the research. It is recommended to further conduct the study for a longer period and include transportation, storage and disposal in the research.

\section{Acknowledgements}

The authors would like to acknowledge the Technical staff in the Departments of Civil and Environmental Engineering and Mechanical and Manufacturing Engineering for services they provided during the case study. The authors will also want to thank the Department of Tertiary Education Funding through Botswana International University of Science and Technology for funding the research. 


\section{Conflicts of Interest}

The authors declare no conflicts of interest regarding the publication of this paper.

\section{Disclosure Statement}

There is no potential conflict of interest to declare.

\section{Funding}

This study was supported by the Ministry of Tertiary Education Research Science and Technology under the Department of Tertiary Education Financing.

\section{References}

[1] Gupta, N., Yadav, K.K. and Kumar, V. (2015) A Review on Current Status of Municipal Solid Waste Management in India. JES, 37, 206-217.

https://doi.org/10.1016/j.jes.2015.01.034

[2] Vitorino de Souza Melaré, A., González, S.M., Faceli, K. and Casadei, V. (2017) Technologies and Decision Support Systems to Aid Solid-Waste Management: A Systematic Review. Waste Management, 59, 567-584. https://doi.org/10.1016/j.wasman.2016.10.045

[3] Miezah, K., Obiri-danso, K., Kádár, Z., Fei-baffoe, B. and Mensah, M.Y. (2015) Municipal Solid Waste Characterization and Quantification as a Measure towards Effective Waste Management in Ghana. Waste Management, 46, 15-27. https://doi.org/10.1016/j.wasman.2015.09.009

[4] Bertanza, G., Ziliani, E. and Menoni, L. (2018) Techno-Economic Performance Indicators of Municipal Solid Waste Collection Strategies. Waste Management, 74, 86-97. https://doi.org/10.1016/j.wasman.2018.01.009

[5] Dehghanifard, E. and Dehghani, M.H. (2018) Evaluation and Analysis of Municipal Solid Wastes in Tehran, Iran. MethodsX, 5, 312-321. https://doi.org/10.1016/j.mex.2018.04.003

[6] Yukalang, N., Clarke, B. and Ross, K. (2017) Barriers to Effective Municipal Solid Waste Management in a Rapidly Urbanizing Area in Thailand. International Journal of Environmental Research and Public Health, 14, 9-14. https://doi.org/10.3390/ijerph14091013

[7] Yoada, R.M., Chirawurah, D. and Adongo, P.B. (2014) Domestic Waste Disposal Practice and Perceptions of Private Sector Waste Management in Urban Accra. BMC Public Health, 14, Article No. 697. https://doi.org/10.1186/1471-2458-14-697

[8] Kgosiesele, E. and Luo, Z.H. (2010) An Evaluation of Waste Management in Botswana: Achievements and Challenges. New York Science Journal, 3, 37-42.

[9] Japanese Government (2013) Scoping Report for the State of Waste Management in and around Gaborone Report Prepared for the Japanese Government. Centre for Applied Research.

[10] Housing Census (2011) Population and Housing Census Population of Towns Villages.

[11] Dangi, M.B., Pretz, C.R., Urynowicz, M.A., Gerow, K.G. and Reddy, J.M. (2011) Municipal Solid Waste Generation in Kathmandu, Nepal. Journal of Environmental Management, 92, 240-249. https://doi.org/10.1016/j.jenvman.2010.09.005 
[12] Troschinetz, A.M. and Mihelcic, J.R. (2009) Sustainable Recycling of Municipal Solid Waste in Developing Countries. Waste Management, 29, 915-923. https://doi.org/10.1016/j.wasman.2008.04.016

[13] Bolaane, B. and Ali, M. (2004) Sampling Household Waste at Source: Lessons Learnt in Gaborone. Waste Management \& Research, 22, 142-148. https://doi.org/10.1177/0734242X04044970

[14] Jadoon, A., Adila, S. and Chaudry, M.N. (2014) Assessment of Factors Affecting Household Solid Waste Generation and Its Composition in Gulberg Town, Lahore, Pakistan. Journal of Materials Cycles Waste Management, 16, 73-81. https://doi.org/10.1007/s10163-013-0146-5

[15] Thanh, N.P., Matsui, Y. and Fujiwara, T. (2010) Household Solid Waste Generation and Characteristic in a Mekong Delta City, Vietnam. Journal of Environmental Management, 91, 2307-2321. https://doi.org/10.1016/j.jenvman.2010.06.016

[16] Al-Khatib, I.A., Monou, M., Abu Zahra, A.S.F., Shaheen, H.Q. and Kassinos, D. (2010) Solid Waste Characterization, Quantification and Management Practices in Developing Countries. A Case Study: Nablus District-Palestine. Journal of Environmental Management, 91, 1131-1138. https://doi.org/10.1016/j.jenvman.2010.01.003

[17] Gomez, G., Ballinas, L. and Castells, F. (2008) Characterization of Urban Solid Waste in Chihuahua, Mexico. Waste Management, 28, 2465-2471. https://doi.org/10.1016/j.wasman.2007.10.023

[18] Owamah, I.H., Izinyon, O.C. and Igbinewekan, P. (2017) Characterization and Quantification of Solid Waste Generation in the Niger Delta Region of Nigeria: A Case Study of Ogbe-Ijoh Community in Delta State. Journal of Material Cycles and Waste Management, 19, 366-373. https://doi.org/10.1007/s10163-015-0426-3

[19] Palanivel, T.M. and Sulaiman, H. (2014) Generation and Composition of Municipal Solid Waste (MSW) in Muscat, Sultanate of Oman. APCBEE Procedia, 10, 96-102. https://doi.org/10.1016/j.apcbee.2014.10.024

[20] Guerrero, L.A., Maas, G. and Hogland, W. (2013) Solid Waste Management Challenges for Cities in Developing Countries. Waste Management, 33, 220-232. https://doi.org/10.1016/j.wasman.2012.09.008

[21] Zhou, H., Meng, A., Long, Y., Li, Q. and Zhang, Y. (2014) An Overview of Characteristics of Municipal Solid Waste Fuel in China: Physical, Chemical Composition and Heating Value. Renewable and Sustainable Energy Reviews, 36, 107-122. https://doi.org/10.1016/j.rser.2014.04.024

[22] Baba, M.T. and Garbi, I. (2012) Evaluation of Moisture Content of Yola Municipality Solid Waste for Energy Production. Journal of Emerging Trends in Engineering and Applied Science, 3, 770-773. 